\title{
Smallholder Farmers' Adaptation Strategies, Opportunities and Challenges to Climate Change: A Review
}

\author{
Sisay Workalemahu, ${ }^{1, *}$, Ibsa Dawid ${ }^{2}$ \\ ${ }^{1}$ Department of Climate Smart Agriculture, Haramaya University, Haramaya, Oromia, Ethiopia. \\ ${ }^{2}$ Socio-Economics Research Team, Asella Agricultural Engineering Research Center, Oromia Agricultural Research Institute, P. \\ O. Box 06, Asella, Ethiopia.
}

\begin{abstract}
How to cite this paper: Sisay Workalemahu, Ibsa Dawid. (2021) Smallholder Farmers' Adaptation Strategies, Opportunities and Challenges to Climate Change: A Review. International Journal of Food Science and Agriculture, 5(4), 592-600. DOI: 10.26855/ijfsa.2021.12.005
\end{abstract}

Received: September 13, 2021

Accepted: October 7, 2021

Published: October 20, 2021

*Corresponding author: Sisay Workalemahu, Department of Climate Smart Agriculture, Haramaya University, Haramaya, Oromia, Ethiopia. Email:

sisayworkalemahu2021@gmail.com

\begin{abstract}
Agricultural production is the primary source of income for most smallholder farmers. Climate change and variability are currently emerging as a major challenge to agricultural production by smallholder farmers who rely on rain-fed agriculture on small farms. The overall goal of this seminar paper was to examine smallholder farmers' adaptation strategies for increasing crop and livestock production in the face of changing climatic circumstances. Review existing crop and livestock production adaptation strategies, adaptation opportunities, adaptation obstacles, and factors that influence crop and livestock production adaptation strategies under changing climatic circumstances were the specific objectives. Smallholder farmers have used a variety of crop and livestock production adaptation strategies to reduce the impact of climate change and variability-related hazards. Awareness raising and capacity developments are the major important adaptation opportunities for reducing the effect of climate change. Human population growth (large family size), inappropriate land use and forest policies, strategies, and programs, low institutional capacity of local bodies, marginalization of local communities, deforestation, overgrazing, soil erosion, and decline in soil fertility are all factors that make it difficult for smallholder farmers to adapt to the effects of climate variability and change. Smallholder farmers' choice of Adaptation Strategies is influenced by agro-ecology, access to climate/weather information, gender, education level, and age of the household head, farm income, non-farm income, credit usage, extension service, and distance from the market center.
\end{abstract}

\section{Keywords}

Adaptation strategies, climate change, smallholder farmers', adaptation opportunities

\section{Introduction}

Agriculture is a vital sector around the world, supporting the livelihoods of the majority of the poor in developing countries. Climate change is predicted to exacerbate the situation, having a significant influence on crop yields, animal production, and rural communities' livelihoods. Climate change and variability are now posing a significant danger to agriculture, food security, and the livelihoods of millions of smallholder farmers [1]. Because most smallholder farmers have limited capacity to adapt to climate change due to their low levels of education, low income, restricted land area, 
and limited access to technical help, markets, and loans. Because rain-fed agriculture is so reliant on rainfall, crop and livestock output is extremely vulnerable to climate change [2]. Crop rotation, the adoption of improved seeds and new crop varieties, fertilizer treatment, irrigation, mixed cropping, and altering sowing dates are some of the key adaptation tactics utilized by smallholder farmers [3], using soil and water conservation measures, as well as engaging in non-farm income activities, changing animal species and breeds, and regulating the time of grazing and reproduction, as well as employing new and/or adapted forage crops, additional feeds, and concentrates were another adaptation options. Climate change adaptation necessitates the integration of scientific knowledge with indigenous knowledge and traditions [4].

While evidence of smallholder farmers' sensitivity to climate change is growing, and interest in maintaining food security in the face of climate change is expanding, adaptation efforts are still hampered by a dearth of data on how smallholder farmers are experiencing and responding to climate change. As a result, this seminar paper examines smallholder farmers' climate change adaptation strategies, opportunities and challenges. Specific objectives:-

$>$ To review the existing small holder farmers adaptation strategies to climate change

$>$ To review the small holder farmers adaptation opportunities to climate change

$>$ To review the small holder farmers adaptation challenges to climate change

$>$ To review factors affecting choice of Adaptation Strategies

\section{Small Holder Farmers Adaptation Strategies, Opportunities and Challenges to Climate Change}

\subsection{Definitions of Concepts and Terminologies}

Adaptation is "the ability to respond and adjust to actual or potential impacts of changing conditions in ways that moderate harm or take advantage of any positive opportunities that the climate may afford" [5].

Adaptation to climate change is the process of adjusting to actual or anticipated climate change and its effects in order to mitigate harm or capitalize on beneficial opportunities [6].

Adaptation Strategiesmeans understanding what climate we are likely to expriences in the future ,and creating proactive plans that take advantage of opportunities and prepare for impacts [6].

Adaptation Opportunities: factors that make it easier to plan and implement adaptation actions, that expand adaptation options,or that provide ancillary co-benefits. These factors enhance the ability of system to retain productivity or functioning [7].

Adaptation Challenges: factors that make it harder to plan and implement adaptation actions. These constraints commonly include lack of resources (e.g., funding, technology, or knowledge) [8].

\subsection{Adaptation Strategies Used by Smallholder Farmers}

\subsubsection{Crop Production Adaptation Strategies}

\section{(1) Irrigation Agriculture}

Climate change is projected to exacerbate existing threats, especially in areas where water scarcity is already a problem. Agriculture necessitates the use of water, which is becoming increasingly limited. Water conservation has been highlighted in climate change and variability adaptation plans to avoid the destructive effects of drought [9]. Irrigation was a potential option for improving agricultural productivity in areas with low rainfall, severe drought, or a dry spell. Farmers' dugouts, dams, and wells for irrigation near their farms or residences could aid with vegetable planting, boosting farm yields [10]. Irrigation was used as a way to enable farmers develop crops without worrying about rain. It is thought to be a good way to improve farmers' access to water and thus their productivity [1]. Irrigation improves agricultural production and stabilizes farmer incomes, but it has depleted groundwater resources due to overexploitation.

\section{(2) Crop diversification}

Crop diversification is the practice of cultivating more than one crop varietys belonging to the same or different species in a given area in the form of rotations and or intercropping [11]. Farmers used crop diversification (mixed cropping, intercropping and dividing farm lands into varying crops) as an adaptation strategy to reduce the adverse effect of climate change [12]. Crop diversity is a method for making the most use of land, water, and other resources while minimizing risk and uncertainty associated with climatic and weather fluctuation [13]. Farmers who conducted various farming operations (vegetables, fruits, animal production, crops, food processing enterprises, etc.) are believed to be less vulnerable to climate change according to Kassem et al. [14]. Similarly, Lalego et al. [15] discovered that mixed cropping is one of the most effective adaptation techniques farmers utilize to deal with the effects of climate change and variability on crop productivity. Diversifying crops have a variety of responses to climatic shocks, pests, and diseases, many of which are favorable [16]. 


\section{(3) Soil Fertilizer}

Climate change can cause land degradation in locations with a lot of rain [17]. Smallholder farmers' production and productivity are dropping as a result of land degradation caused by climate change [12]. Basic ecosystem activities, such as water infiltration and water cycle management, are no longer performed by degraded ecosystems [18]. A majority of smallholders recognized chemical fertilizer use as an adaptive method [1]. Smallholder farmers have used various inorganic fertilizers and local soil fertility management strategies by adding organic fertilizers such as manure or compost to prevent soil erosion effects and boost crop productivity. In the homestead farming practices, mostly organic fertilizer was used.

\section{(4) Soil and water conservation practices}

Most farmers with farm plots with steep slopes in humid, high altitude, and hilly areas are exposed to moving water caused by recurrent flooding, which erodes the valuable top layer of soil containing essential soil nutrients for crop production [19]. Smallholder farmers have substantial challenges due to declining soil fertility as a result of climate change and other causes (e.g., soil erosion) [20]. Soil and water conservation techniques reduce soil loss from farmers' plots, preserving critical nutrients and increasing crop yields [13]. They also benefit neighbors and downstream water users by reducing flooding, improving biodiversity, and reducing sedimentation in waterways. Furthermore, precipitation rapidly penetrates the soil complex because soil organic matter improves soil structure, and infiltration rates typically surpass rainfall rates [18]. According to Vicente and Gao-Lin [21], proper utilization of soil and water resources is required to ensure and enhance human and environmental well-being in the future. Soil and water conservation practices, according to Jiang et al. [22], considerably reduced runoff and sediment output in the watershed.

\section{(5) Improved seeds}

Drought-resistant crop varieties, short maturing and high yielding crop varieties are among the adaptation options used by smallholder farmers across the agro-ecology to both perceived changes in temperature and precipitation, and some crops and crop varieties have been discontinued [23, 24]. By increasing crop output, improved seeds could help to increase food security. Improved varieties or breeds strategies, according to John et al. [20], increase the resilience of smallholder farmer crops to climatic shocks. Improved potato cultivars, according to Sisay Diriba et al. [25], are vital for increasing production and addressing the challenge of food security. New crop varieties may be adopted merely to boost crop productivity and household income. Important adaptation options include the use of new cultivars of established crop species [26].

\subsubsection{Livestock production adaptation strategies}

Smallholder farmers' livestock-based climate change adaptation tactics include changing animal kinds and breeds, providing appropriate water, producing pasture, changing pasture rotation, and regulating grazing and reproductive times. Furthermore, agricultural adaptation alternatives include the use of different and/or adapted forage crops, supplementary feeds, and concentrates. Another adaptation option is to combine animal and cropping systems, which diversifies the farm and so boosts the farmers' adaptive potential. Because some animal species and breeds are better suited to heat stress than others, changing the animal species or breed can be an effective adaptation option [4].

\section{(1) Production adjustments}

Changes in livestock practices could include: (i) Diversification, intensification, and/or integration of pasture management, livestock, and crop production; (ii) changing the timing of operations; (iii) nature and ecosystem conservation; (iv) modifying stock routings and distances; (v) introducing mixed livestock farming systems, such as stall-fed systems and pasture grazing [27]. Another adaptation strategy used by smallholder farmers is the use of emergency fodder during droughts, the multi-species makeup of herds to survive climate extremes, and the culling of weak animals for food during droughts.

\section{(2) Breeding strategies}

Many of the local breeds have already adapted to the tough environment. Developing countries, on the other hand, are often characterized by a lack of technology in livestock breeding and agricultural programs, which could otherwise aid in faster adaptation. Adaptation tactics address livestock's ability to survive, thrive, and reproduce in a variety of situations, including low nutrition, parasites, and diseases [27]. Such measures could include: (i) identifying and strengthening local breeds that have adapted to local climatic stress and feed sources; and (ii) improving local genetics through cross-breeding with heat and disease tolerant breeds. If climate change outpaces natural selection, the new breed's chances of survival and adaptation are jeopardized.

\section{(3) Livestock management systems}

For the rural poor who cannot afford expensive adaptation technologies, efficient and economical adaptation techniques must be created [27]. These could include (i) provision of shade and water to reduce heat stress from increased temperature. Given current high energy prices, providing natural (low cost) shade instead of high cost air conditioning is more suitable for rural poor producers; (ii) reduction of livestock numbers-a lower number of more productive animals leads to more efficient production and lower emissions from livestock production; (iii) changes in 
livestock/herd composition (selection of large animals rather than small); (iv) improved management of water resources through the introduction of simple techniques for localized irrigation (e.g., drip and sprinkler irrigation), accompanied by infrastructure to harvest and store rainwater, such as tanks connected to the roofs of houses and small surface and underground dams.

(4) Capacity building for livestock keepers, market responses, institutional and policy changes and science and technology development

The capacity of livestock farmers and herders to understand and deal with climate change must be improved, as well as their awareness of global developments. Furthermore, training in agro-ecological technologies and practices for fodder production and conservation enhances animal feed supplies and reduces malnutrition and mortality in herds. The farm market could be improved by promoting interregional trade and credit schemes, for example. Subsidies, insurance systems, income diversification techniques, and livestock early warning systems as well as other forecasting and crisis-preparedness systems - could all help with adaptation efforts. Long-term adaptation efforts would be aided by gaining a better understanding of the effects of climate change on livestock, establishing new breeds and genetic kinds, increasing animal health, and improving water and soil management [27].

\subsubsection{Other adaptation strategies}

\section{(1) Labour migration}

Mobility can serve as a means of escaping environmental dangers, hence migration is another adaptive strategy to climate change. Temporary or permanent migration might take place within a country or across countries. It may present opportunities, but it may also present obstacles. Individual migration can help people diversify their income, and if money is transferred back to the village, it can help the entire community. Migration to other climate-vulnerable areas or areas already under population strain, on the other hand, presents obstacles rather than opportunities [27]. In many locations, temporary migration as an adaptive response to climate stress is already evident. The ability to move, on the other hand, is a function of mobility and resources (both financial and social).

\section{(2) Income diversification}

According to Gautam and Andersen [28], one of the most important qualities of rural livelihoods is livelihood diversification. Household diversification occurs for one of two reasons: a push force or a pull factor (rvival-led and opportunity-led diversification). The pull factors are usually favorable (opportunity-driven) elements that cause farm households to vary their farming or cropping practices, whereas the push factors are hard situations that force farm households to diversify their occupations off the farm (survival-driven led). Non-farm diversification techniques are aimed at delivering labor to both wage employment and own firms, while on-farm diversification strategies attempt to increase production and reduce the chance of crop failure [29]. Off-farm income that creates chances for long-term adaptation techniques to climatic unpredictability and change, particularly in rural areas. If one source of income is destroyed, there are still other sources of income available, allowing people and communities to adapt better during disasters and thereby become more resilient [27].

\subsection{Smallholder farmers' adaptation opportunities to climate change}

\subsubsection{Enabling Conditions for Adaptation}

Adaptation opportunities are enabling elements that improve actors' ability to plan and conduct actions to meet their adaptation goal(s) or promote natural systems' adaptive responses to climate risk. As a result, an opportunity differs from an adaptation option, which is a specific method of attaining an adaptation goal (such as developing an early warning system to reduce vulnerability to tropical cyclones) or a plan for ecological system conservation. Adaptation opportunities range from raising awareness of climate change, its repercussions, and the possible costs and advantages of adaptation alternatives to enacting particular policies that create favorable conditions for adaptation implementation [30]. According to Lieske et al. [31], Newton [32], key adaptation opportunities, each represented by multiple illustrative examples were reviewed below:

(I) Awareness rising: Positive stakeholder engagement, communication of risk and uncertaintyand participatory research; (II) Capacity-building: research, data, education, and training, extensions services for agriculture, resource provision, development of human capital and development of social capital; (III) Tools: risk analysis, vulnerability assessment, multi-criteria analysis, cost/benefit analysis, decision support systems, and early warning systems; (IV) Policy: integrated resource and infrastructure planning, spatial planning and design/planning standards; (V) Learning: experience with climate vulnerability and disaster risk, learning-by-doing, and monitoring and evaluation; (VI) Innovation: technological change, infrastructure efficiencies, and digital/mobile telecommunications.

\subsubsection{Ancillary Benefits of Adaptation (Adaptation's Additional Benefits)}

Some adaptation measures may provide ancillary advantages (or co-benefits) in addition to their direct benefits in terms of lowering climate change susceptibility. Two key implications for adaptation planning and implementation arise 
from the possibility for ancillary benefits. First, taking them into account may lead to a more favorable appraisal of the cost-effectiveness of a certain adaptation option. Second, taking into account the ancillary benefits of adaptation may make it easier to integrate it into existing management and decision-making processes [30].

\subsection{Challenges of Climate Change Adaptation Strategies}

According to Tilahun et al. [33], factors challenging the ability of smallholder farmer's to adapt to the impacts of climate variability and change include: human population growth (large family size), inappropriate land use and forest policies, strategies and programs, low institutional capacity of local bodies, marginalization of local communities in decision-making concerning their natural resources conservation and utilization, deforestation, overgrazing, soil erosion and decline in soil fertility, limited access to land (the average landholding size per household is less than 1ha), poor access to planting materials (improved crop seeds, tree seeds and seedlings), lack of data and information on climate change and its impacts.

Smallholder farmer's adaptation to climate change is very much challenged by outbreak of (crop, livestock, human) pests and diseases, limited access to extension services, limited water supply, limited access to health services, limited access to education, training and limited infrastructure (schools, roads, electricity, telephone, potable water reservoirs, irrigation dams), limited access to new skills and technologies, conflicts over scarce resources (grazing lands, water points), poor access to markets and financial resources and services (funding, credits), inappropriate development interventions (e.g., villagization/resettlement), disruption of traditional social networks and transformation to new social relationships, poverty (low income), insecure land tenure and gender inequalities [33, 34].

\subsection{Factors affecting choice of Adaptation Strategies}

\subsubsection{Agro-ecology}

Because of variances in climatic conditions, soil, and other elements, different farmers in different agro-ecological contexts adopt different adaptation methods [35 and 36]. Farmers in the highlands and mid-highlands are more likely than farmers in the lowlands to choose different crops and plant diverse crop varieties, according to Wondimagegn and Lemma [3].

\subsubsection{Access to climate/weather information}

Farmers who are aware of changing climatic circumstances are more likely to take adaptive strategies to mitigate the effects of climate change and variable hazards [13, 37]. Farmers may be able to change their short-term and day-to-day crop and animal management decisions, such as watering crops, harvesting, fertilizing, and livestock diseases, based on daily or weekly weather projections, according to Abid M. et al. [38]. Kinuthia et al. [39] found that farmers who got weather information were more likely to modify planting dates and perform some irrigation as adaptation techniques. Farmers that have more access to climatic information are more motivated to embrace improved crop and livestock types rather than native kinds, according to this study by Frehiwot Assefa [23] and Soglo and Nonvide [40].

\subsubsection{Sex of household head}

At the farm level, the sex of the household head is a significant factor influencing adaptation decisions. Male-headed households had more chances to put adaptation strategies into effect than female-headed households [34]. According to Wondimagegn and Lemma [3], as stated in Alemayehu [41], addressing women organizations and associations can have a considerable positive impact on enhancing smallholder farmers' adoption of adaption methods. According to Ubisi et al. [42], men smallholder farmers adapted better than female farmers by using crop diversification.

\subsubsection{Education level of the household head}

Smallholder farmers who are educated have better access to information, can understand and analyze the situation more easily than those who are not $[43,44,14]$. Farmers with a higher educational attainment are more likely to adopt intercropping to prevent severe climate change consequences, according to Sisay Diriba et al. [25]. Seid Sani et al. [12] and Dembele et al. [45] observed that the literacy status of the household head affects the usage of crop and livestock diversification as adaptation techniques in a significant and favorable way.

\subsubsection{Age of household head}

Farmers with more experience may have a better understanding of the effects of climate change and unpredictability on crop and livestock output, as well as how to adopt adaptation techniques [15]. Older farmers, on the other hand, were more hesitant to incorporate technology improvements into their farming techniques [34, 44]. According to Piya et al. [13], household heads with a higher age and education are less likely to rely on traditional coping mechanisms and are more likely to adopt enhanced adaption practices. The age of the household head is adversely connected with irrigation use, according to Al-Amin et al. [46]. 


\subsubsection{Farm income}

Farm revenue availability, according to Alemayehu [41], improves farmers' financial condition, allowing them to acquire farm inputs such as improved seeds. Farmers with higher earnings have access to important productive resources such as farm assets, inputs, and land, resulting in increased crop and livestock production [45]. Farmers with more money are more likely to adopt climate change measures, according to Ashraf et al. [47, 44]. Adoption tactics are more likely to be adopted as one's income rises. Farm income has a favorable and considerable impact on the usage of enhanced crop and livestock varieties as an adaptation strategy, according to Tarfa et al. [48].

\subsubsection{Non-farm income}

Smallholder farmers' practice other activities, in addition to farming, such as wage labor, making handcrafts [42] guard in the nearby organization (include cooperative association and school), being laborer force in the nearby community, petty trading for income generation. Off-farm activities play a critical role in lowering farm household vulnerability to climate change, but only a small percentage of farmers participate in such activities [23, 49]. This indicates that having off-farm income helps a farmer's financial situation, allowing them to buy farm inputs like improved seeds, breeds, and other supplies for crop and livestock output.

\subsubsection{Credit used}

Credit availability is critical in the adaptation to climate change process [40]. Farmers' financial resources and capacity to meet affordable transaction expenses linked with the different adaption options they might choose to take rose as a result of access to credit [50]. Access to financing is one of the most important elements in farm households' crop and animal diversification decisions, according to Hailu Elias [51] and Tarfa et al. [48].

\subsubsection{Extension service}

The availability of extension services aided in the implementation of climate change adaption methods [52]. To reduce the effects of climate change and enhance crop production and livestock product, it is vital to raise awareness and understanding about the best climate change adaptation options [15]. To put it another way, farmers who have more access to agricultural knowledge and technical help are more conscious of the effects of climate change [38]. Access to extension services was substantial and positive for perceiving fertilizer application, mixed cropping, irrigation, and animal diversification as adaptive strategies, according to Guodaar, L. et al. [1].

\subsubsection{Distance from the market center}

Because the market acts as a means of exchanging knowledge with other farmers, proximity to the market is a significant determinant factor in the employment of adaptation strategies [43]. According to Piya et al. [13], households in remote areas are constrained by a lack of information, a lack of access to markets to sell their products, a lack of off-farm employment opportunities, and a lack of service from development agencies, resulting in less dissemination of information about improved agricultural practices.

\section{Conclusion and Reccomendations}

The most pronounced effects of climate change and variability were decline in soil fertility, erratic rainfall, crop diseases and pests, reduce crop yield and change in livelihood. Important crop production adaptation options being used by smallholder farmers in response to adverse effects of climate change include crop diversification, use of soil fertilizer, planting of drought resistant varieties of crops, change in cropping pattern and calendar of planting, mixed cropping, use of irrigation/improved irrigation efficiency, adopting soil conservation measures that conserve soil moisture, planting of trees and use of improved seeds.

Smallholder farmers livestock based adaptation strategies to climate change includes diversification, intensification and/or integration of pasture management, livestock and crop production, altering the timing of operations, conservation of nature and ecosystems, introducing mixed livestock farming systems, identifying and strengthening local breeds that have adapted to local climatic stress and feed sources and, improving local genetics through cross-breeding with heat and disease tolerant breeds. Major Smallholder farmers challenge to adapt climate change which includes lack of technical knowledge about adaptation strategies, lack of irrigation water, lack of money to finance their adaptation strategies, lack of climate and weather information, lack of improved seeds that adapts the environment, shortage of labor and shortage of land. Agro-ecology, access to climate information, sex, educational level, age, farm income, non-farm income, credit used, extension service and distance to market have significant impact on adaptation to climate change.

Finally, given the diversity of smallholder farmer contexts and climate change experiences, it will be critical to develop flexible adaptation strategies that can be customized to unique farming situations and climatic challenges. Designing and implementing adaptation methods that increase smallholder farmers' resistance to climate change will be difficult, but important if the government is to fulfill its goals of poverty reduction, food security, and economic devel- 
opment. However, in order to construct more effective climate change adaptation strategies, the government must give necessary resources such as money, new technology, knowledge, and extension services.

\section{References}

[1] Guodaar, L., Asante, F., Eshun, G., Abass, K., Afriyie, K., Appiah, D. O., ... Kpenekuu, F. (2019). How do climate change adaptation strategies result in unintended maladaptive outcomes? Perspectives of tomato farmers. International Journal of Vegetable Science, 1-17. doi: 10.1080/19315260.2019.1573393.

[2] Getachew Teferi, Degefa Tolossa, and Negussie Semie. (2018). Perception and Adaptation Strategies of Rural People against the Adverse Effects of Climate Variability: A Case Study of Boset District, EastShewa, Ethiopia. Environmental Development. https://doi.org/10.1016/j.envdev.2018.07.005.

[3] Wondimagegn Tesfaye and Lemma Seifu. (2016). "Climate change perception and choice of adaptation strategies: Empirical evidence from smallholder farmers in east Ethiopia”. International Journal of Climate Change Strategies and Management. Vol. 8, Issue 2: 253-270. doi: 10.1108/ IJCCSM-01-2014-0017.

[4] Gebrehiwot, T. and van der Veen, A. (2013). Farm Level Adaptation to Climate Change: The Case of Farmer's in the Ethiopian Highlands. Environmental Management, 52(1): 29-44.

[5] Echnoserve. (2014). Guideline for Conducting Vulnerability Assessment. Federal Democratic Republic of Ethiopia. Ministry of Agriculture, Addis Ababa, Ethiopia.

[6] LincolnLenderking, H., Robinson, S. A., and Carlson, G. (2021). Climate change and food security in Caribbean small island developing states: challenges and strategies. International Journal of Sustainable Development \& World Ecology, 28(3): 238-245.

[7] Islam, M., S. Sallu, K. Hubacek, and J. Paavola. (2014). Limits and barriers to adaptation.

[8] Dow, K., F. Berkhout, and B. L. Preston. (2013). Limits to adaptation: a risk approach.

[9] Reyes-Paecke, S., Gironás, J., Melo, O., Vicuña, S., and Herrera, J. (2019). Irrigation of green spaces and residential gardens in a Mediterranean metropolis: Gaps and opportunities for climate change adaptation. Landscape and Urban Planning, 182: 34-43. doi:10.1016/j.landurbplan.2018.10.006.

[10] Fagariba, C. J., Shaoxian Song, and Serge Kevin Gildas Soule Baoro. (2018). Climate Change Adaptation Strategies and Constraints in Northern Ghana: Evidence of Farmers in Sissala West District. Sustainability, 10, 1484. doi: 10.3390/su10051484.

[11] Fadina, R. and Barjolle, D. (2018). Farmers' Adaptation Strategies to Climate Change and Their Implications in the Zou Department of South Benin. Environments, Vol. 5, No. 15; doi: 10.3390/environments5010015.

[12] Seid Sani, Jema Haji, and Degye Goshu. (2016). Climate Change Adaptation Strategies of Smallholder Farmers: The Case of Assosa District, Western Ethiopia. Journal of Environment and Earth Science, Vol. 6, No. 7: 9-15.

[13] Piya, L., Maharjan, K. L., and Joshi, N. P. (2019). Adaptation Strategies and Factors Influencing the Adaptation Choices. Socio-Economic Issues of Climate Change, 161-190. doi: 10.1007/978-981-13-5784-8_12.

[14] Kassem, H., Suleiman, A., Alotaibi, B., Aldosri, F., and Straquadine, G. (2019). Climate Change Adaptation in the Delta Nile Region of Egypt: Implications for Agricultural Extension. Sustainability, 11, 685. doi:10.3390/su11030685.

[15] Lalego, B., Ayalew, T., and Kaske, D. (2019). Impact of climate variability and change on crop production and farmers' adaptation strategies in Lokka Abaya District, Southern Ethiopia. African Journal of Environmental Science and Technology, Vol. 13(3). http://www.academicjournals.org/AJEST.

[16] Maharjan, S. K. (2019). Household-Level Factors Affecting the Climate Change Adaptation in Agriculture in Central and Western Nepal. Ecology, Pollution and Environmental science, 2(1): 199-203.

[17] Teklewold, H., Mekonnen, A., and Kohlin, G. (2018). Climate change adaptation: a study of multiple climate-smart practices in the Nile Basin of Ethiopia. Climate and Development. DOI: 10.1080/17565529.2018.1442801.

[18] Kassam, A., Friedrich, T., and Derpsch, R. (2018). Global spread of Conservation Agriculture. International Journal of Environmental Studies. DOI: 10.1080/00207233.2018.1494927.

[19] Bedeke, S., Vanhove, W., Gezahegn, M., Natarajan, K., and Van Damme, P. (2018). Adoption of climate change adaptation strategies by maize-dependent smallholders in Ethiopia. NJAS-Wageningen Journal of Life Sciences. doi: 10.1016/j.njas.2018.09.001.

[20] John K. M. Kuwornu1, Ramatu M. Al-Hassan, Prince Maxwell Etwire, and Yaw Osei-Owusu. (2013). Adaptation Strategies of Smallholder Farmers to Climate Change and Variability: Evidence from Northern Ghana. Information Management and Business Review. Vol. 5, No. 5 : 233-239: (ISSN 2220-3796).

[21] Vicente, M. L. and Gao-Lin, Wu. (2019). Soil and Water Conservation in Agricultural and Forestry Systems. Water, $11: 1937$. 
doi: 10.3390/w11091937.

[22] Jiang, C., Zhang, H., Wang, X., Feng, Y., and Labzovskii, L. (2019). Challenging the land degradation in China's Loess Plateau: Benefits, limitations, sustainability, and adaptive strategies of soil and water conservation. Ecological Engineering, 127: 135-150. doi: 10.1016/j.ecoleng.2018.11.018.

[23] Frehiwot Assefa. (2016). Determenants of Farmers’ Adaptation Strategies to Climate Change and Variability: The Case of Mareka District of Dawuro Zone, South Ethiopia. American Journal of Human Ecology, Vol. 5, No. 1: 20-35. DOI: $10.11634 / 216796221605784$

[24] FAO. (2017). FAO Strategy on Climate Change. Rome.

[25] Sisay Diriba, Mulugeta Damie, and Molla Alemayheu. (2019). Climate change adaptation strategies in response to food insecurity: The paradox of improved potato varieties adoption in eastern Ethiopia. Cogent Food \& Agriculture. DOI: http://dx.doi.org/10.1080/23311932.2019.1640835.

[26] Wrigley-Asante, C., Owusu, K., Egyir, I. S., and Owiyo, T. M. (2017). Gender dimensions of climate change adaptation practices: the experiences of smallholder crop farmers in the transition zone of Ghana. African Geographical Review: 1-14. doi:10.1080/19376812.2017.1340168.

[27] Akinnagbe and Irohibe. (2014). Agricultural adaptation strategies to climate change impacts in Africa: a review. Bangladesh J. Agril. Res., 39(September): 407-418.

[28] Gautam, Y. and Andersen, P. (2016). Rural livelihood diversification and household well-being: insights from Humla, Nepal. Journal of Rural Studies, 44: 239-249.

[29] Bezu, S. and Holden, S. (2014). Are rural youth in Ethiopia abandoning agriculture? World Development, 64: $259-272$.

[30] Midgley, G. F. and Africa, S. (2014). Constraints, and Limits Coordinating Lead Authors: Review Editors. Pp. 899-943.

[31] Lieske, D. J., T. Wade, and L. A. Roness. (2013). Climate change awareness and strategies for communicating the risk of coastal flooding: a Canadian Maritime case example. Estuarine, Coastal and Shelf Science. www.sciencedirect.com/science/article/pii/S0272771413002035.

[32] Newton, P. W. (2013). Regenerating cities: technological and design innovation for Australian suburbs.

[33] Tilahun, M., Angassa, A., and Abebe, A. (2017). Community-based knowledge towards rangeland condition, climate change, and adaptation strategies: the case of Afar pastoralists. Ecological Processes, 6: 29. DOI: 10.1186/s13717-017-0094-4.

[34] Belay, A., Recha, J. W., Woldeamanuel, T., and Morton. (2017). Smallholder farmers' adaptation to climate change and determinants of their adaptation decisions in the Central Rift Valley of Ethiopia. Agriculture \& Food Security. DOI 10.1186/s40066-017-0100-1.

[35] Esayas, B., Simane, B., Teferi, E., Ongoma, V., and Tefera, N. (2019). Climate Variability and Farmers' Perception in Southern Ethiopia. Advances in Meteorology, 1-19. doi: 10.1155/2019/7341465.

[36] Jairo, M. N. and Korir, E. (2019). Climate Knowledge, Adaptation and Intensity of Adaptation Strategies among Farmers in the Slopes of Mount Kenya. Climatol Weather Forecasting. Vol. 7, Iss. 1, No: 246.

[37] Korir, J. C. and Ngenoh, E. (2019). Factors Influencing the Adaptation Decisions to Impacts of Climate Change among the Maasai Pastoral Community in Narok County, Kenya. Agricultural Sciences: 10: 689-705. https://doi.org/10.4236/as.2019.105054.

[38] Abid, M., Scheffran, J., Schneider, U., and Elahi, E. (2018). Farmer Perceptions of Climate Change, Observed Trends and Adaptation of Agriculture in Pakistan. Environmental Management. https://doi.org/10.1007/s00267-018-1113-7.

[39] Kinuthia, K. J., Shadrack K. Inoti, and Lenah Nakhone. (2018). Factors Influencing Farmer's Choice of Crop Production Response Strategies to Climate Change and Variability in Narok East Sub-county, Kenya. Journal of Natural Resources and Development, 2018, 08: 69-77. DOI number: 10.5027/jnrd.v8i0.07.

[40] Soglo, Y. Y. and Nonvide, G. M. A. (2019). Climate change perceptions and responsive strategies in Benin: the case of maize farmers. Climatic Change, 155: 245-256. doi: 10.1007/s10584-019-02452-3.

[41] Alemayehu, D. (2019). Adaptation strategies by smallholder farmers to increase crop production under the changing climatic conditions the case of Gozamin district, East Gojam.

[42] Ubisi, N. R., Paramu L. Mafongoya, Unathi Kolanisi, and Obert Jiri. (2017). Smallholder farmer's perceived effects of climate change on crop production and household livelihoods in rural Limpopo province, South Africa. Change Adaptation Socioecol. Syst., 3: 27-38. DOI: 10.1515/cass-2017-0003.

[43] Yaméogo, T. B., William M. Fonta, and Tobias Wünscher. (2018). Can Social Capital influence Smallholder Farmers' Climate-Change Adaptation Decisions? Evidence from Three Semi-Arid Communities in Burkina Faso, West Africa. Social Sciences, 7: 33. doi: 10.3390/socsci7030033.

[44] Dang, H. L., Li, E., Nuberg, I., and Bruwer, J. (2019). Factors influencing the adaptation of farmers in response to climate change: a review. Climate and Development, 1-10. doi:10.1080/17565529.2018.1562866. 
[45] Dembele, B., Bett, H. K., Maina Kariuki, I., Le Bars, M., and Ouko, K. O. (2018). Factors influencing crop diversification strategies among smallholder farmers in cotton production zone in Mali. Advances in Agricultural Science, 6(3): 01-16.

[46] Al-Amin, Akhter, T., Islam, A., Jahan, H., Hossain, M. J., Prodhan, M. M. H., Kirby, M. (2019). An intra-household analysis of farmers' perceptions of and adaptation to climate change impacts: empirical evidence from drought prone zones of Bangladesh. Climatic Change. doi:10.1007/s10584-019-02511-9.

[47] Ashraf, M. Q., Khan, S. A., Muhammad R. K., and Iqbal, W. (2018). Determinants of Adaptation Strategies to Climate Change by Farmers in District Sargodha, Pakistan. Journal. Int. J. Econ. Environ. Geol., 9(1): 16-20.

[48] Tarfa, P. Y., Ayuba, H. K., Onyeneke, R. U., Idris, N., Nwajiuba, C. A., and Igberi, C. O. (2019). Climate change perception and adaptation in Nigeria's guinea savanna: empirical evidence from farmers in Nasarawa State, Nigeria. Applied Ecology and Environmental Research, 17(3): 7085-7112.

[49] Weldlul Ayalew. (2016). Analysis of Smallholder Farmers' Perceptions of Climate Change and Adaptation Strategies to Climate Change: The Case of Western Amhara Region, Ethiopia. Doctor of Philosophy in Environmental Management. Univeristy of South Africa.

[50] Tessema, Y. A., Joerin, J., and Patt, A. (2018). Factors affecting smallholder farmers' adaptation to climate change through non-technological adjustments. Environmental Development, 25: 33-42. doi:10.1016/j.envdev.2017.11.001.

[51] Hailu Elias. (2016). Welfare Implications of Credit Constraints and Climate Change Adaptation Strategies on Ethiopian Farm Households. Phd Dissertation. Addis Ababa University. Addis Ababa, Ethiopia.

[52] Nkuba, M., Chanda, R., Mmopelwa, G., Kato, E., Mangheni, M., and Lesolle, D. (2019). "The effect of climate information in pastoralists' adaptation to climate change: A case study of Rwenzori region, Western Uganda”. International Journal of Climate Change Strategies and Management. https://doi.org/10.1108/IJCCSM-10-2018-0073. 